\title{
The Role of Quality Improvement in the Innovation practices in SMEs in Latvia
}

\author{
Ketevan Rizhamadze ${ }^{1,{ }^{*}}$ and Anna Ābeltina ${ }^{2,{ }^{* *}}$ \\ ${ }^{1}$ MBus (Global Business Analysis), Doctoral student, Turiba University, Rīga \\ ${ }^{2}$ D.Sc. (Economics), Associate Professor, EKA University of Applied Science, Rīga
}

\begin{abstract}
The hasty pace of globalization depicted by fundamental changes in the production technologies is utterly altering international trade. Furthermore, the rapid technological transformation requires organizations to refer to quality improvement while introducing innovative services and products. The following study scrutinizes the role of quality improvement in the innovation within the SMEs operating throughout Latvia. The nature of the study is quantitative and the views of SMEs representatives were captured via an online survey. SMEs operating in the field of manufacturing and retail in Latvia were selected for the participation in the study. As the research results reveal, quality improvement is considered as an important factor upon which innovative activities are implemented. Besides, in the rapidly changing consumer needs, product quality improvement is seen as a process of modifying and redesigning the products and services to satisfy well swiftly fluctuating demands for SMEs. In addition, our research discloses that the major sectors in Latvia within which quality management systems certification was requested were: construction, transportation, communication, wholesale and retail trade. Furthermore, research findings show that financing of productive capacity is central to any development strategy, but access to finances still remains a major obstacle for SMEs.
\end{abstract}

\section{Introduction}

In this rapidly changing world, customer demands evolve and proposing innovative products and services tend to be pivotal for organizations. It is empirically evidenced that companies that exploit their creativity and innovation tend to be profitable and their market share is increased [1]. Innovation is a drive to prosperity and it is profoundly reliant on management and not just a technological innovation. Innovation management implies that a firm's structure, norms and practices might evolve for the purpose of establishing technological and innovative base upon which competitive advantage is gained [2]. Managers should ensure that relationships are well managed and conflicts within the organization are properly resolved. Firms succeeding in managing complex relationship patterns would reap the benefits of fierce competition [3]. Moreover, the more advanced the

\footnotetext{
*Corresponding author: katerizhamadze@gmail.com

**Corresponding author: anna.abeltina@gmail.com
} 
company is, the more ability it possesses to make alterations and improve itself [4]. As there exist diverse quality management programs, the organizations are facing the dilemma of selecting the program that efficiently and effectively corresponds to their needs [5]. The process of quality improvement in the organization can cover various actions like benchmarking, reengineering, upgrading, etc. [6]. As a matter of fact, the business process implies phases upon which an input is transformed into a viable output. In addition, a continuous process improvement forms a particular course of enhancement that is based on business strategy [7]. The other challenge that the organizations have to overcome is differentiating innovation and improvement. Continuous improvement relies on the enhancement of existing products and services. Whereas, innovation requires breakthroughs and process disruptions [4]. SMEs, known as a heterogeneous population of firms have an impact upon process of innovation and to economies. The contribution and engrossment could be expressed in various methods. Innovative products could be created by using research and development (R\&D) inputs or without it. The SMEs that are present in high technological industries rely on science based knowledge to practice innovation. However, SMEs working in low technological settings, don't refer to R\&D for innovation purposes [8]. In developing countries, the role of SMEs is meaningful in job creation and in economic development. They account for more than $90 \%$ of businesses and above $50 \%$ of employment globally. One of the main obstacles for SMEs to grow and to extend their operations, appears accessibility to financial means [9]. Struggles faced by SMEs in accessing bank finance are hindering economic development in all sectors in Latvia. Therefore, putting emphasis on the area of cross-border, e-commerce and focusing on productivity, growth and export tend to be fundamental to the development of Latvian economy [10].

\section{$1 \mathrm{SMEs}$ and innovation in Latvia}

In 2016 Latvia became member of the OECD (The Organization for Economic Cooperation and Development) and in 2014 joined the Eurozone. Agriculture, chemicals, logistics and woodworking are the cornerstones of the Latvian economy [11]. SMEs contribute hugely in non-financial business economy of Latvia. SMEs and large firms created employment opportunities and added value at an analogues degree during the period of 2014-2018 [10]. Even though the principal source of funding for SMEs tend to be EU funds, Latvia currently undergoes difficulties as numerous EU funding lines are expiring and there is a harsh decrease of economic relations with Russia [11]. Moreover, country faces a challenge to improve the skills and innovation via vocational training. As a result, it would be beneficial for Latvian companies to reap the benefits of digital skills derived from life-long learning programs. Even though the total valued added to the total employment in Latvia is above the respective EU averages and is $79.4 \%$, the average productivity is half than the EU average as illustrated in Table 1. 
Table 1: Value added of SMEs

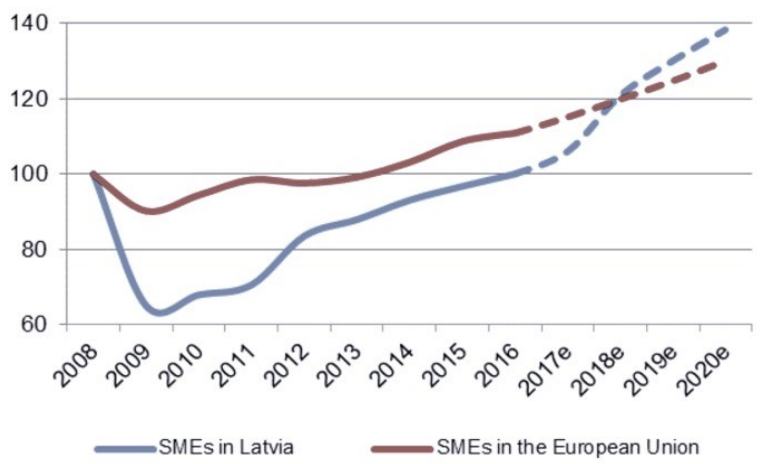

Source: European Commission 2021, [5]

Manufacturing, wholesale \& retail trade are chief sectors that add value and create employment in EU countries and Latvia is no exception. As illustrated in Table 2, SMEs in Latvia employ around 4.6 people that tends to be the above EU average of 3.9.

Table 2: Number of persons employed in SMEs

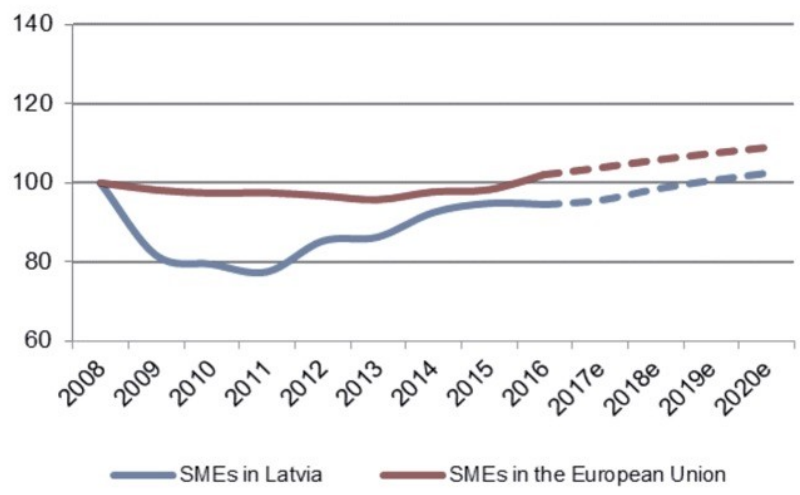

Source: European Commission 2021, [5]

Micro firms are defined as organizations that hire up to nine persons, small firms employ from 10 to 49 persons and firms that employee from 50 up to 249 persons are considered as medium sized enterprises. As illustrated in Table 3, small firms contribute greatly in adding the value. Micro companies were the major contributors in terms of employment growth. The increase in manufacturing production and e-commerce were evident and it had effect upon growth. 
Table 3: SMEs basic figures, Number of persons employed in SMEs

\begin{tabular}{|c|c|c|c|c|c|c|c|c|c|}
\hline $\begin{array}{c}\text { Class } \\
\text { size }\end{array}$ & \multicolumn{2}{|c|}{ Number of enterprises } & \multicolumn{2}{|c|}{ Number of persons employed } & \multicolumn{3}{c|}{ Value added } \\
\hline & \multicolumn{2}{|c|}{ Latvia } & EU-28 & \multicolumn{2}{|c|}{ Latvia } & EU-28 & \multicolumn{2}{|c|}{ Latvia } & EU-28 \\
\hline & Number & Share & Share & Number & Share & Share & Number & Share & Share \\
\hline Micro & 104,705 & $91.6 \%$ & $93.0 \%$ & 217,364 & $33.2 \%$ & $29.7 \%$ & 2.7 & $21.0 \%$ & $20.8 \%$ \\
\hline Small & 7,976 & $7.0 \%$ & $5.9 \%$ & 158,454 & $24.2 \%$ & $20.1 \%$ & 3.1 & $23.9 \%$ & $17.6 \%$ \\
\hline $\begin{array}{c}\text { Medium- } \\
\text { Sized }\end{array}$ & 1,450 & $1.3 \%$ & $0.9 \%$ & 143,879 & $22.0 \%$ & $16.8 \%$ & 3.4 & $26.3 \%$ & $18.0 \%$ \\
\hline SMEs & 114,131 & $99.8 \%$ & $99.8 \%$ & 519,697 & $79,4 \%$ & $66.6 \%$ & 9.3 & $71.1 \%$ & $56.4 \%$ \\
\hline Large & 195 & $0.2 \%$ & $0.2 \%$ & 135,144 & $20.6 \%$ & $33.4 \%$ & 3.8 & $28.9 \%$ & $43.6 \%$ \\
\hline Total & 114,326 & $100.0 \%$ & $100.0 \%$ & 654,841 & $100.0 \%$ & $100.0 \%$ & 13.1 & $100.0 \%$ & $100.0 \%$ \\
\hline
\end{tabular}

Source: European Commission 2021, [5]

According to small business act of European Commission, the weakest performing area for Latvia is skills and innovation. In addition, compared to other EU countries, Latvia is lagging behind on digitalization of activities [10]. In addition, the growth is hampered by weak innovation and inefficient resource allocation. Compared to other OECD countries, Latvia is behind other EU countries, in terms of implementing innovation by the business field. In addition, the amount dedicated to R\&D activities is low within the OECD [12]. There is also lack of talent in this field and the scarcity of skilled professionals hampers the development and proper implementation of innovative activities as illustrated in table 4:

Table 4: Skills and innovation

\begin{tabular}{|c|c|c|}
\hline Area & Latvia & $\begin{array}{c}\text { EU } \\
\text { average }\end{array}$ \\
\hline Introduction of new products and processes by SMEs & $18.68 \%$ & $33.32 \%$ \\
\hline $\begin{array}{c}\text { Introduction of organizational and marketing } \\
\text { innovations by SMEs }\end{array}$ & $21.41 \%$ & $33.43 \%$ \\
\hline $\begin{array}{c}\text { In-house innovation by SMEs } \\
\text { Cooperation of SMEs with other companies }\end{array}$ & $15.2 \%$ & $28.95 \%$ \\
\hline SMEs selling online & $10.33 \%$ & $12.23 \%$ \\
\hline Turnover from e-commerce & $5.36 \%$ & $10.13 \%$ \\
\hline Percentage of enterprises employing ICT specialists & $14.04 \%$ & $18 \%$ \\
\hline$\%$ of enterprises ensuring CT skills learning to staff & $9.56 \%$ & $21.22 \%$ \\
\hline
\end{tabular}

Source: Elaborated by authors based on Small Business Act, Latvia 2019, [5]

As the problem persists in the area of skills and innovation, since 2014 policy interventions focus on supporting the policies that improve and strengthen these activities. Policy measures and support programs are developed to ensure and to improve innovation capacity of SMEs. The models developed by European commission sets the rules and guidelines for cooperation among research institutes and organizations [10]. Moreover, by ensuring the quality cooperation between scientific institutions and companies innovation ecosystem will be reinforced and digital technologies shall be disseminated broadly throughout the economy [12]. Following the ranking of European innovation scoreboard, Latvia falls in a moderate category. The differences between EU and Latvia are illustrated in the table below. 
Table 5: European innovation scoreboard, 2020

\begin{tabular}{|c|c|c|}
\hline Description & Latvia & EU \\
\hline Turnover share SMEs (\%) & 52.8 & 38.3 \\
\hline Launching new firms (>10 staff) (\%) & 1.9 & 1.1 \\
\hline Entrepreneurship (\%) & 14.8 & 6.7 \\
\hline $\begin{array}{c}\text { R\&D expenditures } \\
\text { (per 10 mln population) }\end{array}$ & 0.0 & 16.2 \\
\hline $\begin{array}{c}\text { Easiness of commencing a business } \\
\text { (max.100) }\end{array}$ & 80.2 & 76.5 \\
\hline
\end{tabular}

Source: Elaborated by authors based on

European Innovation Scoreboard 2020, [6]

As the figures demonstrate the revenues generated by SMEs tend to exceed the average amount among European Union members. The firm's birth is $1.1 \%$ in EU and in Latvia it's higher and tends to be $1.9 \%$. In entrepreneurship activities, Latvia has also higher percentage and sets the percentage at $14.8 \%$. However, there is a different situation when it comes to $R \& D$ expenditures. The $R \& D$ spending is negative and is lower than the average. When it comes to ease of starting a business, the figure is positive and tends to be above the EU average. As the figures in table 6 illustrate, the weakness is remarkable in innovation capacity for star-ups [13]:

Table 6: The Community Innovation Survey (CIS), 2018

\begin{tabular}{|l|l|l|}
\hline \multicolumn{1}{|c|}{ Description } & $\begin{array}{c}\text { Indicator scores } \\
\text { Latvia }\end{array}$ & $\begin{array}{c}\text { Indicator scores } \\
\text { EU }\end{array}$ \\
\hline Product innovation presented by SMEs & 134 & 123 \\
\hline $\begin{array}{l}\text { Business process innovation presented } \\
\text { by SMEs }\end{array}$ & 106 & 109 \\
\hline $\begin{array}{l}\text { Cooperation of SMEs with other } \\
\text { companies }\end{array}$ & 112 & 141 \\
\hline Non-R\&D innovation expenses & 61 & 103 \\
\hline
\end{tabular}

Source: Elaborated by authors based on community Innovation Survey (CIS). [6]

\section{Previous researches}

The research conducted by Kotane and Kuzmina-Merlino concludes that generally the performance of the SMEs is evaluated based on the financial figures, however it tends to be insufficient and other indicators that demonstrates the revenues should be scrutinized [14]. According to research conducted by Riekstina and Zvirgzdina, reveals that micro and small firms are presented in overwhelming numbers in the total number of Latvian companies. In addition, following main sectors were identified: wholesale, retail trade, financial \& insurance activities and construction [15]. The research conducted by Vasilevska and Rivza identified that problems related to the operation of quality management systems in SMEs were: financial expenditures necessary for staff training and certifications, as well as long term implementation of the system and sustaining and maintaining the system in place [16]. In order to examine the quality management system, it is advisable to scrutinize the results of the Survey for 2019 which shows an estimation of the number of valid certificates issued by the International Organization for Standardization (ISO). The ISO survey results consists of three sets of the data: the number of valid certificates, the number of sites covered by the certificates and the number of sectors. The number of valid certificates issued in Latvia were 889 within 1031 sites as illustrated in Table 7 below: 
Table 7: ISO 9001:2015 Quality management systems

\begin{tabular}{|c|c|}
\hline \multicolumn{2}{|c|}{ Latvia } \\
\hline Certificates & $\mathbf{8 8 9}$ \\
\hline Sites & $\mathbf{1 0 3 1}$ \\
\hline Source: Elaborated by authors based on the ISO Survey, [7]
\end{tabular}

The major sectors in Latvia within which ISO 9001 certification was requested were: construction, transport, storage and communication and wholesale \& retail trade. The data is illustrated in the Table 8:

Table 8: ISO 9001:2015 Quality management systems

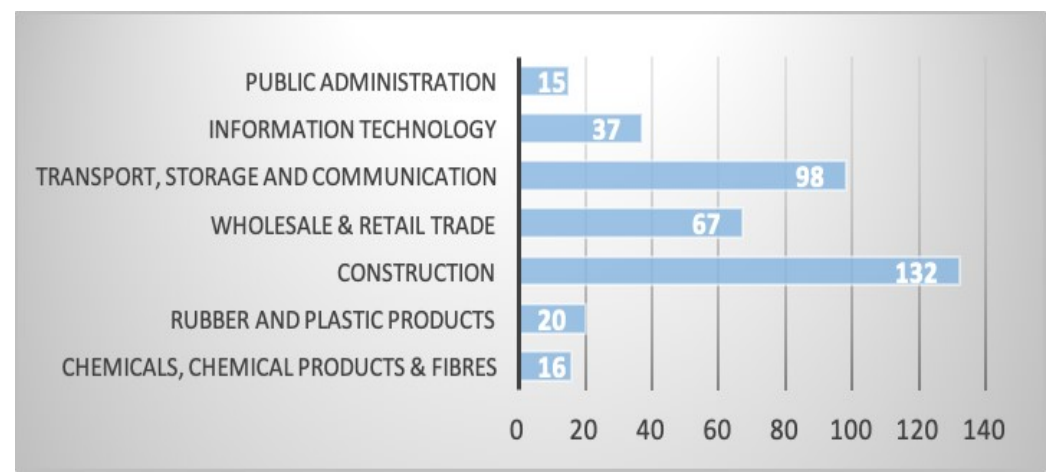

Source: Elaborated by authors based on the ISO Survey, [7]

Previous researchers have identified four broad strategic types of SMEs:

- $\quad$ Firms that are concerned with progression;

- Firms that are concerned with customer demands;

- Firms that are concerned with product development;

- Group of firms without having clear strategic direction

The categorization of strategic types, gives an opportunity to managers and entrepreneurs to comprehend well strategic course and their attitudes towards global functioning of firms [17].

\section{Overall aim of the research and methodology}

The main aim of the study to identify a significant platform upon which innovation practices are implemented. In addition, to address the relationship between quality improvement and innovation in SMEs. The target of the study is SMEs working in the manufacturing and retail. In addition, we posit that quality improvement is considered as an important factor upon which innovation is build and developed. Furthermore, this paper empirically considers that internal factors that exist in the organization, contribute greatly in regulating the link among innovative activities and quality management.

The nature of the study is primarily quantitative. The views of SMEs representatives were captured through an online survey. SMEs operating in the field of manufacturing and retail in Latvia were selected. The participants of the survey were chosen based on their scope of activities. Contact information was obtained through official registry of companies. The criterion of selection was the following: firms with more than ten staff members up to 250 
employees were eligible to participate in the survey. Nevertheless, participation in the survey was voluntary and questionnaire was used as a research instrument. The questionnaire was administered online and survey was distributed among SMEs via company's official e-mails. Survey included both closed and open questions. Closed questions gave the respondents a chance to select the answer from pre-defined Reponses. In addition, the questionnaire included 'yes' or 'no questions along with multiple choice questions. The summary of research methodology is illustrated in table 9:

Table 9: Research Methodology

\begin{tabular}{|l|l|}
\hline Research methodology & Quantitative \\
\hline Data & Secondary/ Primary \\
\hline Paradigm & Positivism \\
\hline Research type & Analytical(Exploratory) \\
\hline Research outcome & Pure \\
\hline Logic of the research & Deductive \\
\hline Sample size & $\mathbf{1 1 0}$ SMEs \\
\hline The margin of error & $\mathbf{5 \%}$ \\
\hline Uncertainty margin & $\mathbf{9 5 \%}$ \\
\hline Survey completion rate & $\mathbf{8 6 . 3 0 \%}$ \\
\hline
\end{tabular}

Source: Elaborated by the authors

Following research limitations were identified: the number of the units of analysis used in the study is dictated by the type of specific research problem. As sample size is not large, it will be difficult to ensure a representative distribution of the population. In addition to sample size, there are lack of prior research studies on the topic and study will be conducted in Latvia only. Samples readiness in participating and prone to bias can also be added limitations to the research.

\section{Research findings}

The research findings reveal that within internal factors, innovation is considered to be an essential feature upon which the firm's growth is achieved. In addition, the results reveal that $95 \%$ of participants deem that innovative activities do have an influence upon firm's growth and development. Study finding demonstrate that innovation is considered as an important practice that has effect upon growth and firm's development. In addition, per participants responses, human, technological resources, organizational structures and systems endorse firm growth (See Figure. 1). 
Figure 1: Internal factor for growth

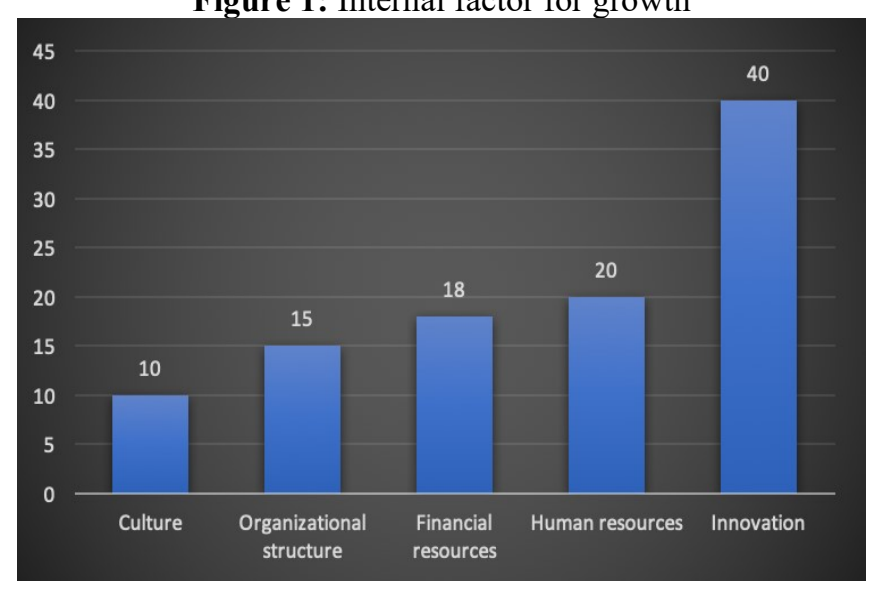

Source: Elaborated by the authors

In the survey, there were more participants from medium-sized enterprises than there were from small organizations, $52 \%$ and $48 \%$ respectively (See Figure 2).

Figure 2: The breakdown of participants of the survey

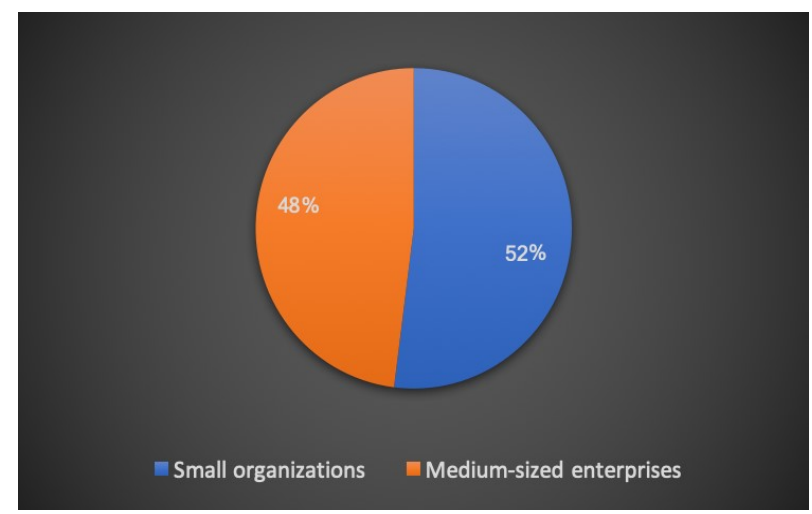

Source: Elaborated by the authors

Pursuant to study findings, the platform that SMEs generally rely on for implementing innovation practices is quality improvement. For them, improving quality or adding value to existing products and services tend to be the platform upon which innovation practices are implemented. Alongside quality improvement, market competition and added value to customers is also considered to be important platform for innovation practice drive $26 \%$ and $21 \%$ respectively. As illustrated in below table, the majority of respondents, $35 \%$ consider quality improvement as an essential platform for implementing innovation (see Figure 3). 
Figure 3: Base for innovation

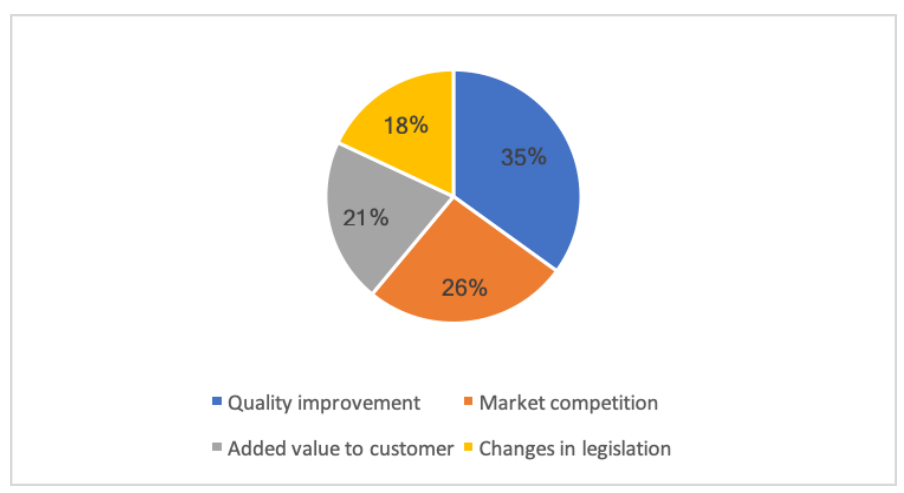

Source: Elaborated by the authors

Even though, quality improvement was cited as an important platform that drives innovation, implementing it in practice is complicated for SMEs. As survey results show, the major challenge for it is access to finances [18]. Majority of survey respondents not only regard access to finance as an impediment for product development, but also as a huge hindrance to growth, productivity and form's development. Competitor's response to market changes and legal environment have also a major role in firm's growth and development (See Figure 4).

Figure 4: Outer factor that endorse growth

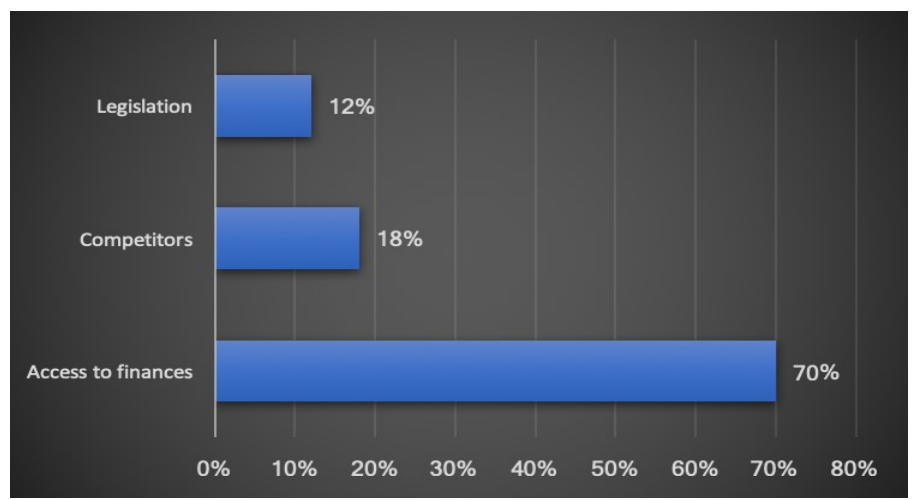

Source: Elaborated by the authors

The research findings demonstrate that, innovation process that is linked with quality improvement is present in up to $45 \%$ of SMEs. However, small firms are hesitant to conduct research and development activities as it is associated with additional finances. However, while redesigning product and adding new features to existing products small firms are referring to innovation for quality improvement.

\section{Conclusion}

The SME sector is a backbone for a number of developed and emerging economies thus assisting and complementing larger firms. SMEs play a crucial role in the world economy 
and contribute substantially to income, output and employment. In today's changing world innovation and quality management is becoming one of the key drivers for change. However, global financial crisis and increasingly fast technological changes created a particularly tough climate for SMEs. The lack of innovation strategy, well defined and structured quality improvement process, and performance indicators are rarely assessed due to lack of structures and systems in place. The issues of innovation and quality improvement is pivotal, especially when competitive advantage of SME's is highly dependent on it. From management side of view, managing these processes is even complicated and requires special attention and tactics. Present research proposal has been planned with a view to discuss the various issues related to the SME's. In order to meet a wide scope of international development goals, it is necessary to ensure and guarantee that SME's are given possibilities and opportunities where they can exhibit their full potential and skills especially in developing countries. Following major findings emerge from the different analyses presented in the study:

- SME tend to be the main creators of jobs in Latvia and major contributors to national economy;

- Quality improvement is considered as a significant base upon which company implements its innovation activities;

- The major sectors in Latvia within which quality management systems certification was demanded were: construction, transport, communication, wholesale and retail trade;

- Quality improvement is considered to be an important factor to implement innovative activities broadly;

- SMEs are less likely to conduct comprehensive research and development activities due to lack of accessibility to finances

Based on the study and survey findings, pursuing innovation is a key to productivity and creativity. Continuous innovation will make business more competitive and profitable. For quality enhancement and improvement, it is vital to conduct researches. If small and medium sized enterprises wish to grow, to become innovative and to add features to existing products it is suggested to refer to researches frequently. However, R\&D is associated with finances and SMEs usually lack additional financial resources, it is less probable that they will conduct research activities.

\section{References}

1. Maital S., and Seshadri D.V.R. Innovation management: Strategies, concepts and tools for growth and profit. New Delhi: Sage. P38 (2017).

2. Volberda, H. W., Van Den Bosch, F. A., Heij, C. V. Management innovation: Management as fertile ground for innovation. European Management Review, 10, 1 15 (2013). [Online]. Retrieved on February 15, 2021 from https://doi.org/10.1111/emre.12007

3. Ābeltina, A., Rizhamadze, K. The complexity of relationships within business and the importance of common ground. SHS Web of Conferences, 90, 01001 (2021). https://doi.org/10.1051/shsconf/20219001001.

4. Boonstra, J. J. Dynamics of organizational change and learning. Chichester: Wiley (2008).

5. Backström, T., Fundin, A., Johansson, P. E. Innovative Quality Improvements in Operations Introducing Emergent Quality Management. Cham: Springer International Publishing (2017).

6. Møller, C. and Chaudhry, S. S. Advances in enterprise information system II proceedings of the fifth international conference on recearch and pratical issues of 
entreprise information systems (CONFENIS 2011), Aalborg, denmark, October 16-18, 2011. New York: CRC Press (2012).

7. Plenert, G. J. Strategic continuous process improvement. New York: McGraw-Hill Professional (2012).

8. Organisation for Economic Co-operation and Development, OECD. Enhancing the competitiveness of SMEs in the global economy: strategies and policies. Conference for Ministers responsible for SMEs and Industry Ministers Bologna, Italy, 14-15 June 2000. [Online]. Retrieved on February 07, 2021 from http://www.oecd.org/cfe/smes/2010176.pdf

9. World Bank. Official web-site. [Online]. Retrieved on February 20, 2021 from https://www.worldbank.org/en/topic/smefinance

10. European Commission, EC. SME Performance Review, Small Business Act (SBA) 2019, Latvia. [Online]. Retrieved on 21 February, 2021 from https://ec.europa.eu/growth/smes/sme-strategy

11. The Innovation Policy Platform, IPP. official website. [Online]. Retrieved on February 21, 2021 from

https://www.innovationpolicyplatform.org/www.innovationpolicyplatform.org/content /latvia/index.html

12. Organisation for Economic Co-operation and Development, OECD (May, 2019)

Economic Surveys, Latvia. [Online]. Retrieved on February 21, 2021 from

http://www.oecd.org/economy/surveys/latvia-2019-OECD-economic-surveyoverview.pdf

13. European Union, EU. European Innovation Scoreboard 2020 [Online]. Retrieved on February 2, 2021 from https://ec.europa.eu/info/index_en

14. Kotane, I., and Kuzmina-Merlino, I. Analysis of small and medium sized Enterprises' business performance Evaluation practice at transportation and storage services sector in Latvia. Procedia Engineering, 178, 182-191 (2017). [Online]. Retrieved on February 19, 2021 from https://doi.org/10.1016/j.proeng.2017.01.093

15. Riekstina, I., Zvirgzdina, R. Small business in Latvia - trends and facts in five years. Economic Science for Rural Development. (2019)

https://lufb.llu.lv/conference/economic_science_rural/2019/Latvia_ESRD_50_2019169-176.pdf

16. Vasilevska, D., and Rivza, B. Implementation of quality management in small and medium enterprises: Problems and solutions. Engineering for Rural Development. (2018)[Online]. Retrieved on February 21, 2021 from http://www.tf.llu.lv/conference/proceedings2018/Papers/N116.pdf

17. Birgit Hagena, Antonella Zucchella, Paola Cerchiellob, Nicolò De Giovannic (June 2012). International strategy and performance - Clustering strategic types of SMEs. International Business Review, 21, June 2012, Pages 369-382. [Online]. Retrieved on February 6, 2021 https://doi.org/10.1016/j.ibusrev.2011.04.002

18. International Organization for Standardization, ISO. The ISO Survey. [Online]. Retrieved on February 21, 2021 from https://www.iso.org/the-iso-survey.html 